\title{
A trait-based approach to thermal niches: linking movement and metabolism to predict thermal tolerances of terrestrial invertebrates
}

\author{
Jördis Terlau ${ }^{1}$, Thomas Boy ${ }^{1}$, Ulrich Brose ${ }^{2}$, Benoit Gauzens ${ }^{3}$, Malin Pinsky ${ }^{4}$, Samraat \\ Pawar $^{5}$, and Myriam Hirt ${ }^{3}$ \\ ${ }^{1}$ German Centre for Integrative Biodiversity Research (iDiv) Halle-Jena-Leipzig \\ ${ }^{2}$ German Centre for Integrative Biodiversity Research Halle-Jena-Lepizig \\ ${ }^{3} \mathrm{iDiv}$ \\ ${ }^{4}$ Rutgers University \\ ${ }^{5}$ Imperial College London
}

February 1, 2022

\begin{abstract}
The survival of animals under global warming strongly depends on their individual thermal niches, which result from the balance between energy loss and gain. Active movement is an important component of this energetic balance, as it affects not only energy gain via food intake but also energy loss via activity metabolism. Here, we develop a novel trait-based approach for how thermal niches arise from temperature-dependent movement. Therefore, we used image-based tracking to quantify the unimodal responses of the movement speed of carabid beetles to temperature. We used these empirical data to parameterize a mathematical model based on metabolic and predator-prey theory for net energy gain to derive a general mechanistic concept of thermal niches. This trait-based approach allows a relatively rapid and cost-effective assessment of climate change vulnerability for a wide range of animal taxa on broad geographic scales.
\end{abstract}

\section{Hosted file}

manuscript_movement_energy_2022-January.docx available at https://authorea.com/users/ 458337/articles/554907-a-trait-based-approach-to-thermal-niches-linking-movement-andmetabolism-to-predict-thermal-tolerances-of-terrestrial-invertebrates

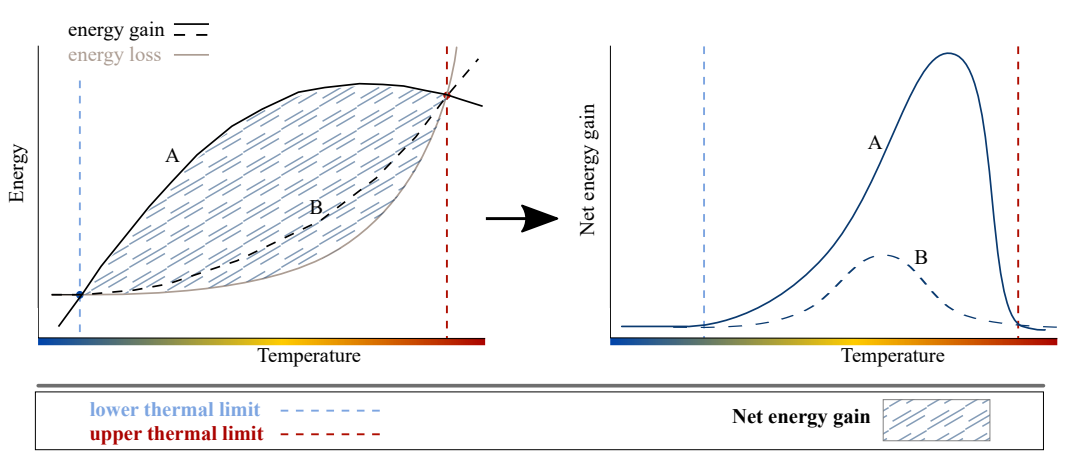




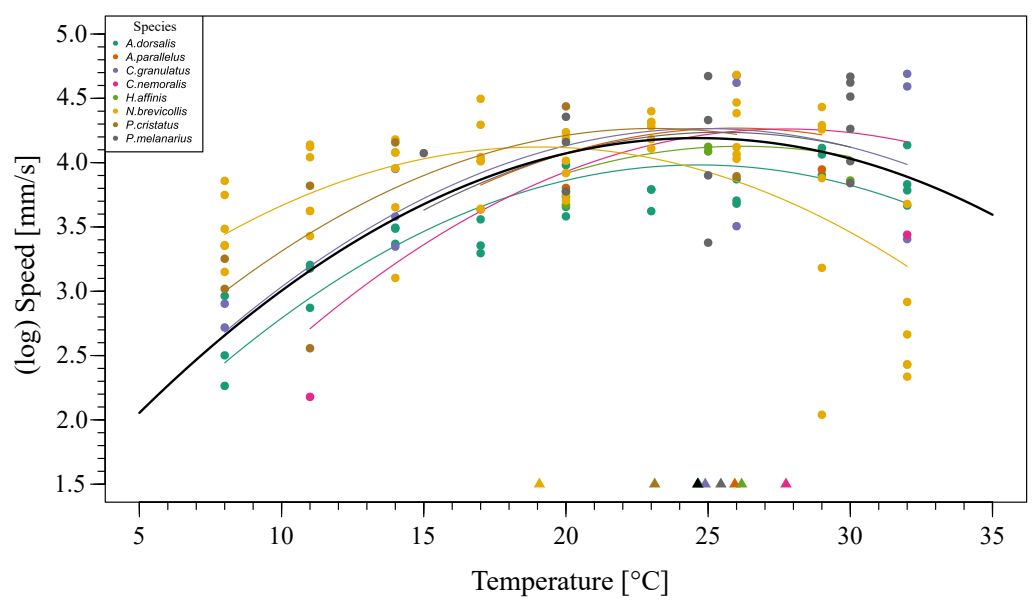

a
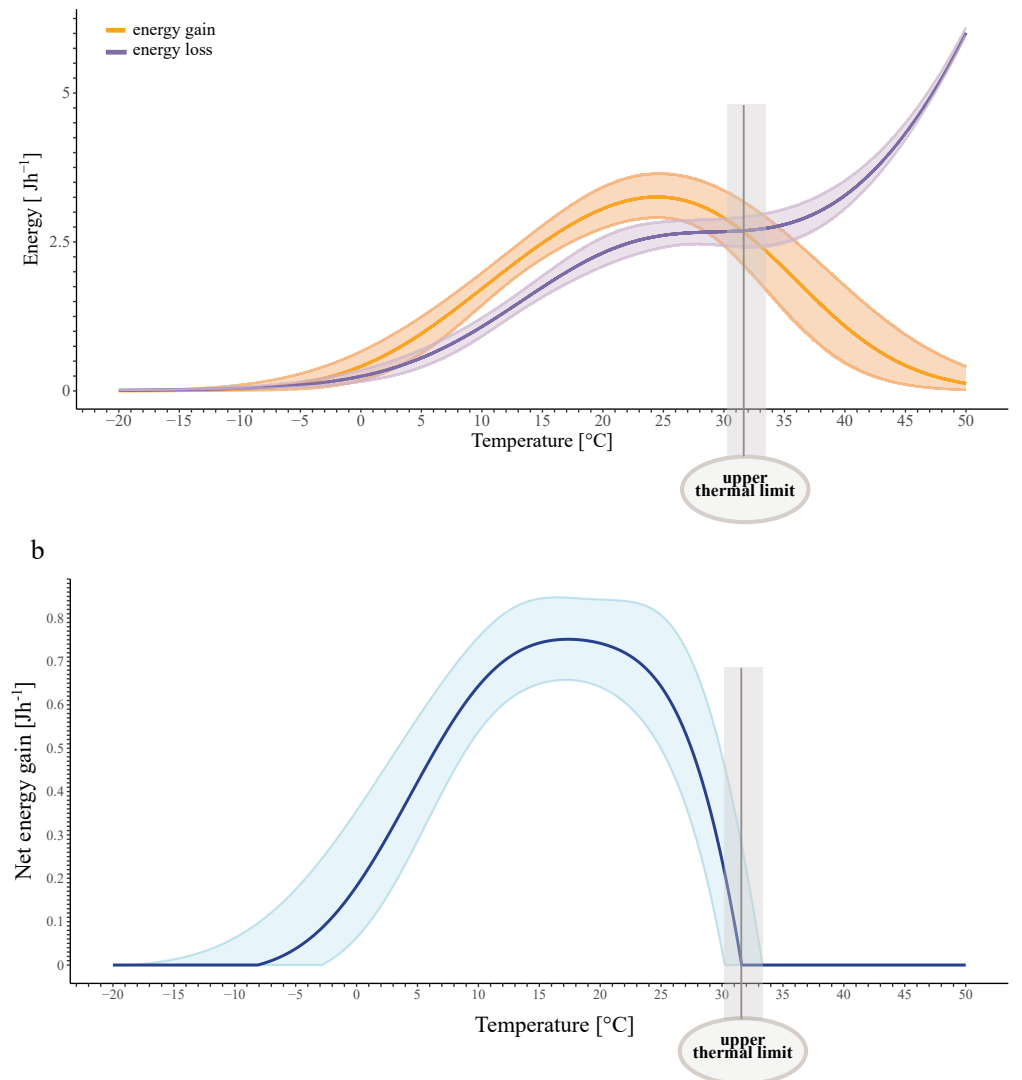


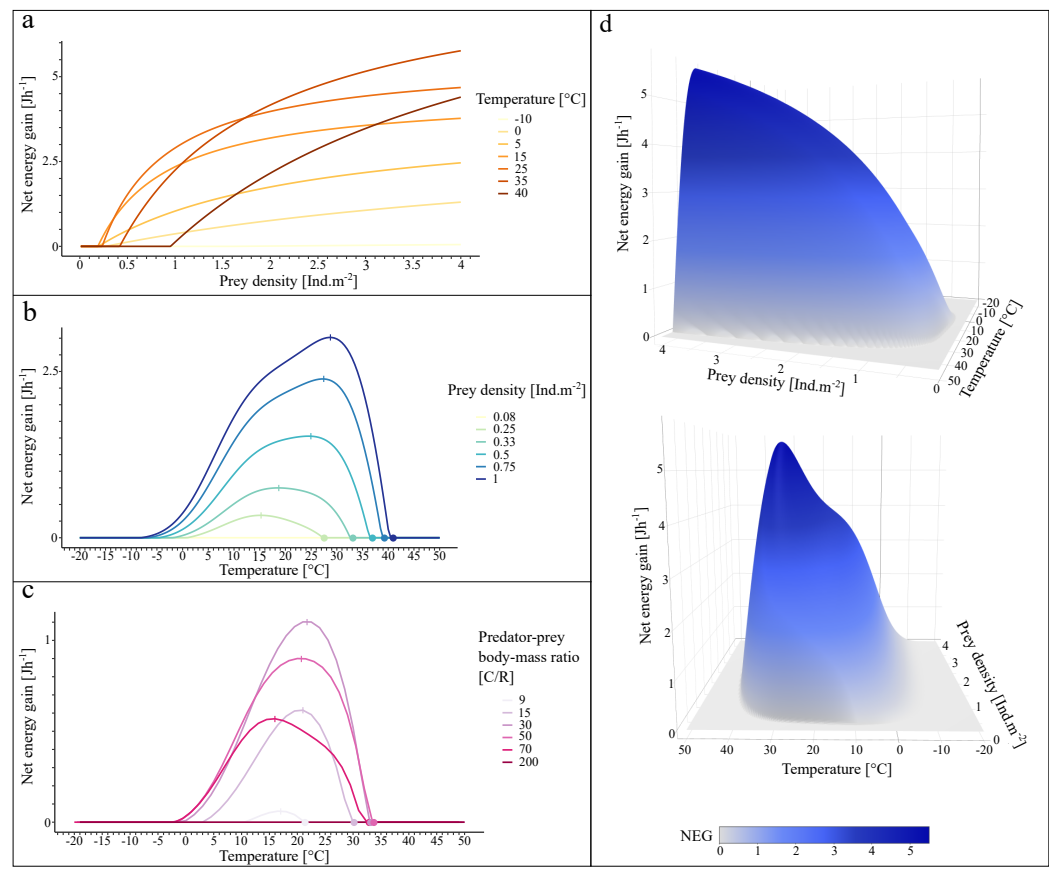

(a)
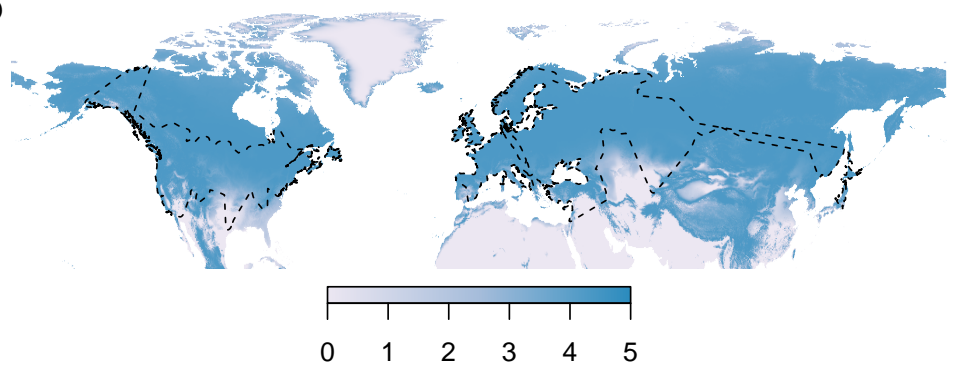

Current net energy gain $\left[\mathrm{Jh}^{-1}\right]$

(b)

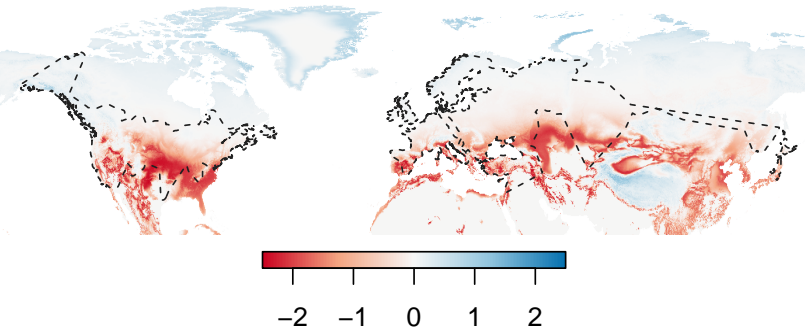

Change in net energy gain $\left[\mathrm{Jh}^{-1}\right]$ 